\title{
ASSESSMENT OF THE DEGREE OF THE PROFUNDITY OF SPECIAL EDUCATIONAL NEEDS
}

\author{
Jan Michalík \\ Vít Voženílek \\ Palacky University Olomouc, Czech Republic
}

\begin{abstract}
The article provides information on extensive research of the profundity (degree) measurement of special educational needs (SEN) of children, pupils and students with disablement in the Czech Republic. The research was based on more than 80 thousands records of contacts with children with disablement. The authors answer the following questions: Are there any differences in the assessment of the SEN for each type of disablements? Are there any differences in the same assessment for each type of educational consultancy facilities? Which methods of the assessment of the SEN's extent are available (and which are required)? What are the consequences of incorrect diagnostics of SEN? The research has shown an inadequate legislative expression of procedural assessment of the impact of disablement for the education purposes. It also confirmed that very few suitable standardized measuring tools are available in the area of special pedagogical diagnostics (as opposed to psychological diagnostics).
\end{abstract}

Keywords: equal access, non-discrimination, special educational needs, disablement, diagnostics of special educational needs, educational psychological centres

\section{Introduction}

Education of children with health disability is in most European countries managed by means of the term 'special education needs', which is a term attempting to emphasize the impacts of the particular disability on education. (In this text the authors shall ignore the fact that special education needs hereinafter SEN has in fact every child or pupil...)

In most European countries (fully applicable to former so called socialist countries) the transition from historically prevailing model of special (or rather segregated) education to education in natural conditions of common schools was and is solved. It is the symbol of SEN that is becoming in a way a label entitling besides other things to drawing adequate adaptation, forms, methods, evaluation and possibly also content of the education volume in the given country (Michalík et al., 2001). The effort to find a non-discrimination and open model of education has become the quality criterion of education systems (not only) in Europe. The prevailing trend in OECD (OECD, 2001) countries is opening a general education stream for this group of pupils (to a various extent and different ways) and the declared endeavour to reach the maximum possible degree of development in the personality of the given pupil. At the same time the correct understanding (diagnostics) of the particular disability of a child or pupil and finding corresponding means of support that are necessary to provide in order to compensate for the diagnosed disability are becoming more and more important. 
The term 'children with special education needs' is by itself a term from the English language environment and it is often criticized (comp. Eddy, 2013; Reynolds \& Fletcher, 2002). It is also possible to use the term from the German language environment 'Kinder mit sonderpädagogischen Förderbedarf'. In the Czech Republic the group of pupils with SEN includes mainly:

- health disability,

- social disadvantage,

- health disadvantage,

- gifted and talented pupils.

Most approaches based on the acknowledgement of SEN have in common the fact that they assess impacts of a disadvantage (e.g. health disability) on education 'horizontally'. These basis classification systems (school legislative and also special needs categories) distinguish, for example, the types of health disability (typically mental, physical, visual, hearing, speech, autistic spectrum disorders). However, all of them are limited in diagnosing the degree of SEN, i.e. the extent of limitations caused by the existence of the given disadvantage, and they influence educational needs and possibilities (comp. Frederickson \& Cline, 2003; Meyen \& Skrtic, 1995).

The guideline for gradual change in the national approaches is represented by International Classification of Functioning, Disability and Health (hereinafter ICF) which is a part of the classification file issued by the World Health Organization. ICF concentrates on the description of assessing health fitness for work, special needs within the education process, assessment of long-term disadvantageous state of health for the reason of granting social security falls among other activities. Its goal is to offer standardized terminology and a scale for description of health and states that relate to health (WHO, 2001).

Special Education Centres are the element that is responsible for conducting entrance and continuing assessments of the impacts of disadvantage on education in individual countries. In the Czech Republic there are Special Education Centres (SECs) for pupils with health disability and EducationalPsychological Centres (EPC) for other pupils. In EPC general, psychological support is provided for pupils. It is often visited by pupils with behaviour disorders and learning disabilities.

The above stated has become the input for a unique research focused on the national level. In 2011 a team of specialists from Palacky University Olomouc with consultants collected data from 86 SEC in the whole country.

The SECs' activities affect the success of training tens of thousands of children. In many studies, the high dependence of families caring for children with disabilities in institutions, advisory and consulting field were confirmed. Questions of optimization of network devices, as well as the availability of services for the target group are widely discussed in the Czech Republic. However, the discussion is so far without processing adequate measurements and analyses by means of special education and also by spatial (territorial) 
approaches. Therefore, the authors developed a new system of measuring the availability of counselling and diagnosis of SECs which resulted in a unique set of data and cartographic output (Dvorský, Snášel \& Voženílek, 2009, 2010). Emerged technologies, mainly geographic information system (GIS) tools, were applied for the spatial information integration of all investigated activities and for the advanced processing in order to detect all the arguments for the network optimization and the SEC activities (Voženílek, 2002, 2009).

\section{Goal, problem, questions}

The goal of the research and mapping was to prove if (and what) there exist differences in the activity of SEC according to their specialization on individual health disabilities. The authors measured within the SECs for pupils with physical, visual, hearing, speech disability and pupils with autistic spectrum disability (ASD) and also clients with a combined disability.

So called the depth of special educational needs as a reflection of the deficit in the state of health (but it is not direct correlation!) is a substantial criterion for setting the correct level of special education support for a pupil at school. It has not a negligible economic importance. Even in the educational system the crisis of the welfare state finds its reflection (Michalík, 2011). Therefore many countries are concerned with the idea to find a form of economic security of necessary support for a group of pupils with SEN, which would take into account more precisely the depth of their handicap.

The first, essential step of any measure is to analyse a situation, with emphasis on the existence of national characteristics and traditions. The relatively simpler situation may occur in the smaller countries of the unitary model of public administration (eg. Lithuania, Latvia). Greater difficulties arise in countries like the Czech Republic, where due to the reform of public administration since 2003 the responsibility for regional education (primary and secondary) has been entrusted to regional authorities - 14 regions the Czech Republic including the capital Prague. In practice, for almost ten years we have seen a gradual transition to a ' 14 national education systems' and despite the fact that the basic instruments (educational programs, inspection, financing - subject) remained within the scope of a central authority - the Ministry of Education.

\section{Methodology}

The authors based their research on an objective assessment of the availability of appropriate services of the SECs in terms of their spatial locations within the whole country, to assess as many their aspects as possible, for example the volume, type and selected aspects of their activities. This aim was fulfilled through geovisualization of results of investigated themes.

The comprehensive pilot survey verifying the content and structure of captured data on services was designed and brought logically-structured SEC data 
datasets for further processing. Pilot data collection which was attended by SEC of two NUTS3 regions was conducted from September to December 2010. The record of each 'SEC educator's contact with the client' was the basic element to verify (and subsequently to use during the actual data collection) in the pilot testing. Therefore, each SEC employee recorded specific range of information about each contact with the client. To ensure anonymity necessary personal information such as name, exact date of birth and address of residence were not recorded. However data on gender and age of client, type and severity of his disability, and other were monitored. Geolocations of records were made by postcode of residence of the client and the place where the SEC educator contacted the client (Tuček, Pászto \& Voženílek, 2009).

The SEC employee used the paper form to notice all required information about the meeting with a client (or immediately after). Once a week, all paper forms were recorded through a web form project. Two-stage data collection (first fill out the paper form and then copy it into the web form) was designed from two reasons. The staffs in SEC usually do not use a computer during contact with the client and in many cases (diagnosis, screening) the typing of records could acted inappropriately and disturbing. The data was stored in the database for further processing in geographic information system. After optimization of survey information in the pilot survey the web page for data input system was adapted to be easy for the SEC staff.

In 2011, from January to December, the authors and their consultants in SECs performed collecting information and field offices in 86 SECs in all regions of the Czech Republic (excluding the capital Prague) as a main survey. Data on contacts of SEC focused exclusively on children and students with mental disabilities were not collected due to wide network of this type SEC. In contrast, the SECs focused on other disability are established in only one region (rarely some regions are without any centre). For the entire period of data collection (except for pilot collection), over 76000 records of client service provided by the SEC were captured. The gathering of such a large volume of information involved collecting data by almost two hundred professionals of regional authorities and particular SECs from all over the country.

\section{Results}

The comprehensive charts (Fig. 1) show the results of SEN diagnostic activities at a depth of six groups of heath disability for the whole Czech Republic.

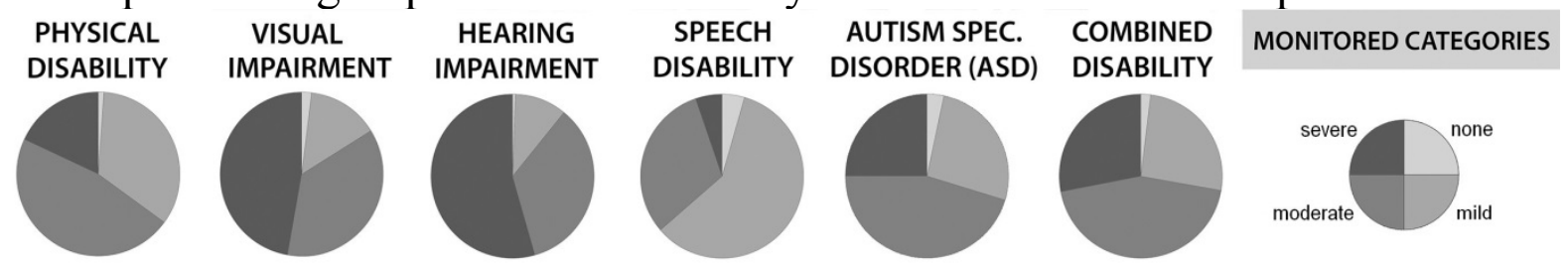

Figure 1 Proportions of the SEC clients according to degree of disabilities diagnosed in the SECs (for the whole Czech Republic in 2011) 
The measured data showed that the clients for which no disability depth was declared after the examination - the depth of SEN, represent the activities of SEC of minority group clients (usually up to $4 \%$ ). Relatively, the largest group consisted of those pupils at SEC for speech disability (SD). It is logical - it was the result of targeted screening, which these workplaces carry out on hundreds of kindergartens and primary schools. The depth of the given disability in the degree of 'light' was found in most of its activities by staff of SEC for SD. And it was more than in $60 \%$ of cases. This is the basic characteristic of this disorder and relatively increasing proportion of children who are in preschool and early school age has underdeveloped communication skills. Perhaps it is the result of new patterns and trends of preschool and home rising of children. In this category, the majority of SECs for students with multiple disabilities and ASD stated about $27 \%$ of all clients. Conversely, centres for pupils with hearing and visual impairment in this group dictated only about $10 \%$ of clients. We have already mentioned the dominant part of these clients in the centres for SD, the second place - about $33 \%$ of clients are centres for individuals with physical disabilities.

Moderate degree of disability (as a basis for diagnosis of SEN) was mostly noted by workers of SPC for physically disabled, ASD and pupils with multiple disabilities, always at about $46-48 \%$ of all clients in a given year. In this case, we observe almost the same proportion of this group of clients at SEC for the hearing impaired and visually impaired people (about 40\%). The SECs reported the lowest proportion of clients in this group according to the depth for SD $(31 \%)$.

Finally, the most serious disability (and thus adequately the greatest degree of SEN) was observed in the SECs for the visually and hearing impaired (48 resp. $55 \%$ ) of all clients. The lowest rate - adequately to previous data was recorded in this monitored item by SEC for SD (about $5 \%$ of clients). The SECs for ASD and combined disability note that the depth of disability - SEN at about $1 / 4$ clients. It is about $20 \%$ of all clients of the SECs for physically disabled. 


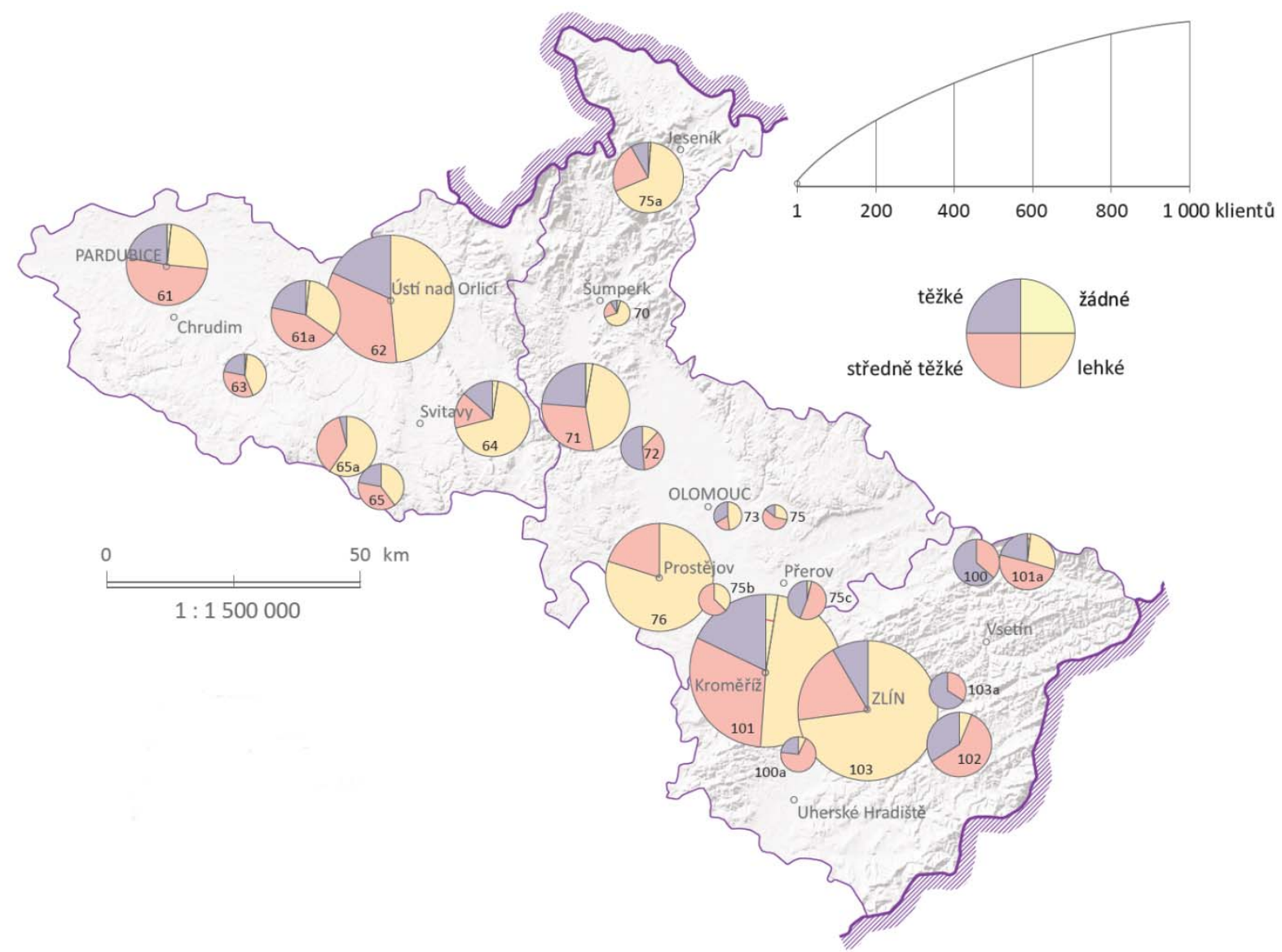

Figure 2 SEC clients with mental disability according to the depth of disability in NUTS3 regions Pardubice, Olomouc and Zlín in 2011. Explanations of sectors: yellow - none disability, orange - mild disability, red - moderate disability, violet - severe disability.

Data on students with learning disabilities were given the extent collected only in three regions.

Even so, it is clear that the SECs for mentally disabled people in these regions have found moderate disabilities (less than half of the clients), followed by a third of clients with moderate disabilities and less than a quarter of clients with the most severe disabilities. However, the map in figure 2 confirms the significant disparities in the diagnostic capability of each SEC. For example the SEC with ID 100 (see Fig. 2) has no record of either the client with mild disabilities, and vice versa with a majority of clients with the most severe disabilities.

Information about the inconsistent diagnostic approach of SEN in the Czech Republic clearly is confirmed in following graphs (Graphs 1 and 2). The authors present results for students with ASD and than diagnosis covering all of about 80 thousand clients across the country. 


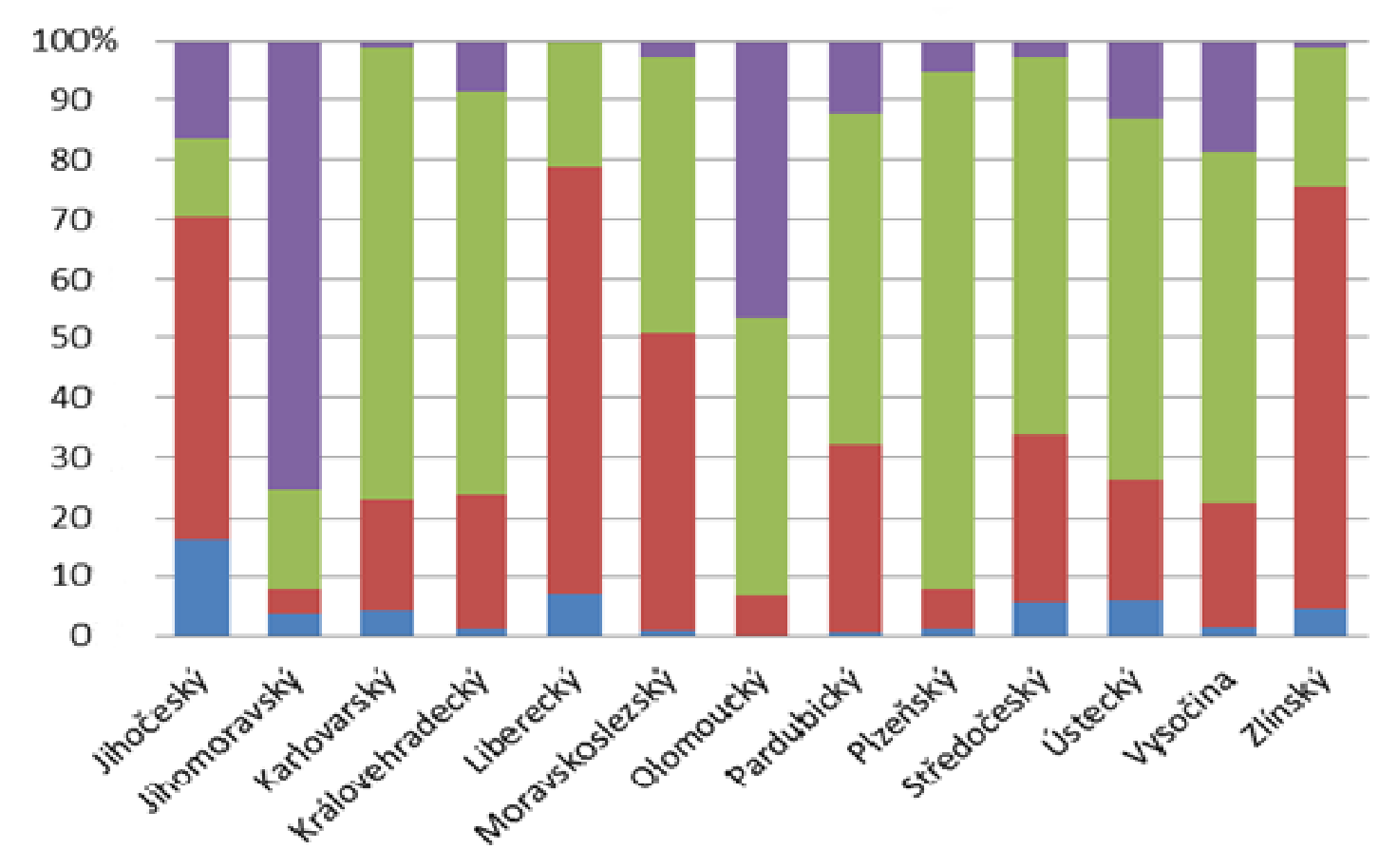

Figure1 Proportions of degrees of ASD in regions according to diagnosis by SECs. Explanations of colours: blue - none, red-mild, green-moderate, violet-severe disability.

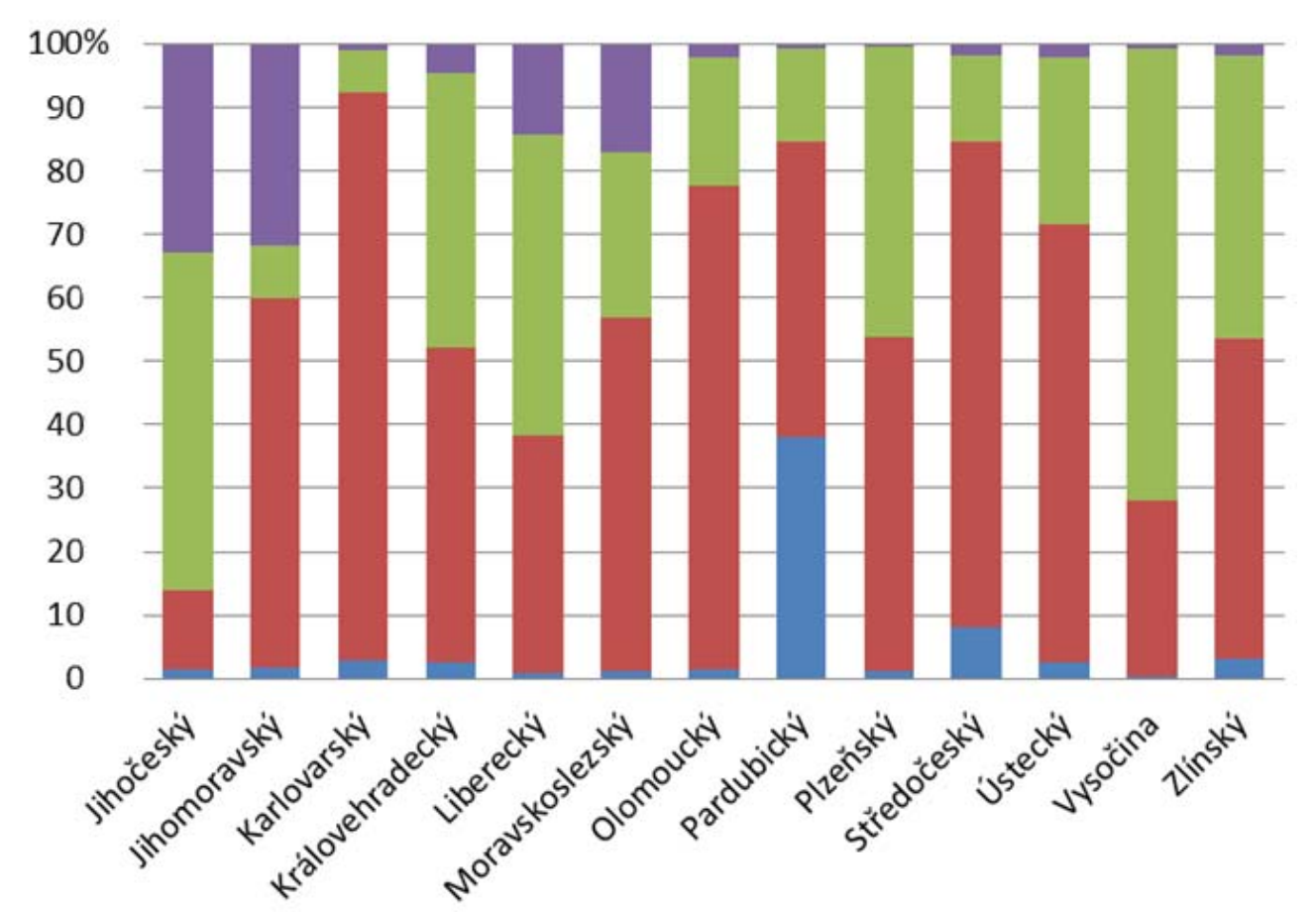

Figure 2 Proportion of degrees of all disability in regions according to diagnosis by the SECs. Explanations of colours: blue - none, red-mild, green-moderate, violet-severe disability. 


\section{Discussion}

The measured results are only partially explainable and justifiable with respect to differences of clients in each region and localization of SECs in the Czech Republic. Given the above and the number of contacts (more than 80,000 in one year) it can be expected that the existence of an objective, accurate, standardized and uniform methodology for the assessment of the SEN and thus the depth of the disability would prevent the situation where some regions show during the year 10 times more clients with the most severe disabilities than other regions.

Striking is the outcome of SECs focused on ASD. In two Czech regions the SECs shows for local pupils severe disability in negligible $1-2 \%$ of clients, in three regions the number was about $2-5 \%$ of the clients. Conversely, in one region it was reported $75 \%$ of students with ASD as a category of students with the most severe type of disability. These varied data cannot be, during the objective validity of the Gaussian frequency distribution, explained otherwise than by the absence of uniform rules that would be able to express special education depth diagnostics of SENs transparently and objectively throughout the country.

The measured results are particularly important in the planning and decision making activities of a public authority in education. They can be considered as a serious argument of inconsistency assessment of the SEN, but they should not be seen as a criticism of counselling centres.

Within the considered model of the transition to the provision of the so called support measures in education in the $\mathrm{CR}$, it is necessary to solve any interference of primary assumption of public resources in the education of this group of students. SEN as a concept will remain, but will be met by providing the necessary support measures currently being considered for five different levels according to the depth of SEN.

The prerequisite is a crucial task to ensure a comparably performing diagnostics of a need for support measures in both here monitored areas:

- the territorial aspect of equality of access - i.e. SEC for the given type of disability in different regions of the country mutually,

- special educational and diagnostic model assessment of the SEN - depth of disability between different groups of students with disabilities.

\section{Conclusions}

The paper brings the results of a large slice of measuring the rate of SEN, here aimed at a depth of disability expressed as a result of special educational diagnosis SECs carried out in the Czech Republic. The existence of objectively unjustifiable differences in assessing the depth of disabilities was confirmed and a conclusion was stated on the impossibility of a fair setting of the support / support measures for pupils who are not provided with objective, comparable 
and standardized diagnostic depth of their SEN. Research results can be used in the preparation of legislative measures in the amendment to the Education Act. The authors express the belief that ICF is the supporting guidance for setting comparative assessment approach (not only) in the EU.

The survey continued in analyses and then in final synthesis of an extensive set of information. The results prove very large scope of SECs activities. Their interpretations also confirm irreplaceable of SEC, especially in relation to identifying means of special educational support of individual children.

In 2012, the authors published the results of above-mentioned research in the 'Atlas of activities of special education centres in the Czech Republic' (Voženílek \& Michalík et al., 2013). The atlas provides a comprehensive overview of the activities of the SECs in the Czech Republic, including the historical development of the network of these institutions. The map products on this topic have not yet been published separately, so the Atlas is a unique presentation of spatial characteristics, together with an evaluation of interdependencies.

\section{Acknowledgements}

The authors gratefully acknowledge the support by the ESF Operational Programme Education for Competitiveness CZ.1.07/1.2.00/14.0020 and CZ.1.07/2.3.00/20.0170 of the Ministry of Education, Youth and Sports of the Czech Republic.

\section{References}

1. DVORSKÝ, J., SNÁŠEL, V. \& VOŽENÍLEK, V. (2009). Map Similarity Testing Using Matrix Decomposition. 2009 International Conference on Intelligent Networking and Collaborative Systems (INCOS 2009), 290-294.

2. DVORSKÝ, J., SNÁŠEL, V. \& VOŽENÍLEK, V. (2010). On maps comparison methods. 2010 International Conference on Computer Information Systems and Industrial Management Applications, CISIM 2010, art. no. 5643513, 557-562.

3. EDDY, L. 2013. Caring for children with special healthcare needs and their families. USA: Wiley - Blackwell.

4. FREDERICKSON, N. \& CLINE, T. (2003). Special education needs, Inclusion and diversity. Open University Press.

5. MEYEN, E. \& SKRTIC, T. (1995). Special education. Student Disability. Love Publishing Company.

6. MICHALÍK, J. (2011). Citizens with disability - Crisis of the Welfare State in Europe? Social Welfare: interdisciplinary Approach, 1, No. LT-76285, 8-15.

7. MICHALIK, J. et al. (2011). Zdravotně postižení a pomáhající profese. Praha, Portál.

8. OECD. 2000. Knowledge and Skills for Life. First Results from PISA 2000. Paris.

9. REYNOLDS, R. \& FLETCHER, E. (2002). Concise encyclopedia of special education. John Wiley.

10. TUČEK, P., PÁSZTO, V. \& VOŽENÍLEK, V. (2009). Regular use of entropy for studying dissimilar geographical phenomena. Geografie, 114(2), 117-129.

11. VOŽENÍLEK, V. (2002). Geoinformatic literacy: Indispensability or nonsense? [Geoinformatická gramotnost: nezbytnost nebo nesmysl?] Geografie, 107(4), 371-382. 
12. VOŽENÍLEK, V. (2009). Artificial intelligence and GIS: mutual meeting and passing. 2009 International Conference on Intelligent Networking and Collaborative Systems (INCOS 2009), 279-284.

13. VOŽENÍLEK, V. \& MICHALÍK, J. et al. (2013). Atlas of Special Education Centres in the Czech Republic [Atlas speciálně pedagogických center v České republice]. Olomouc, Univerzita Palackého v Olomouci.

14. WHO. (2001). International Classification of Functioning, Disability and Health.

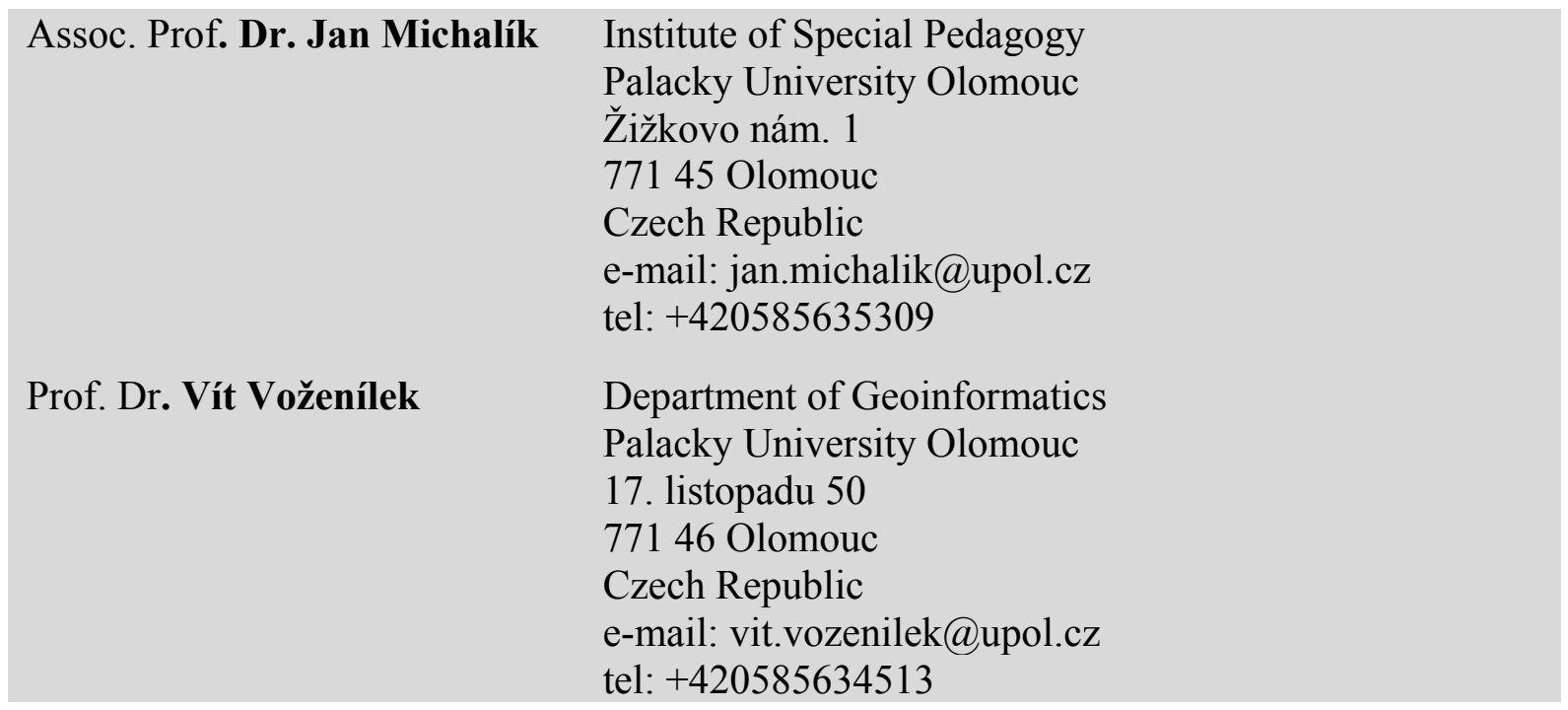

